\title{
An Empirical Study on Promotion Strategy of Private College Teachers' Sense of Efficacy on Western Regions
}

\author{
Lizhen Wang ${ }^{1}$ \\ ${ }^{1}$ Xi'an Internatinal University, Xi'an, Shaanxi, 710077 \\ 59624917@163.com
}

Keywords: Western Regions; Private College; Sense of Efficacy

\begin{abstract}
Development of higher education needs high quality of teachers and universities. The development of the western region of private colleges also needs high-quality teachers. The method to improve teaching efficacy of teachers in the development of university teachers' quality building is playing continuous appreciation in the university teaching quality effective measures. This article will explore how to improve teacher evaluation system so that it plays an important role in university reform and promotes mutual communication between teachers and train teachers to explore self-reflection ability.
\end{abstract}

\section{Introduction}

In the current new situation in Western Region Private Colleges face external pressures and challenges, the need for regional specialties western infrastructure quality teachers to keep private education continued development of the situation. In order to improve the western region of teaching ability and mental health level private colleges and universities, this article will explore how the rapid development of higher education today, private institutions for the western culture and construction of high-level teachers, in a prominent western characteristic while making teachers in private college efficacy has also been added.

\section{A Sense of Self-Efficacy in College Teachers}

American psychologist Albert Bandura published a "self-efficacy: a comprehensive theory of behavioral change," an article in 1977 in which self-efficacy is a person's subjective conjecture and judge their own success, which includes the results expected and efficacy expected [1]. Which improve the efficacy of teachers can be divided into: general education efficacy and personal teaching efficacy of two aspects, while the function of self-efficacy, mainly through four processes play a regulatory role of human functioning. These four processes are cognitive and motivational processes, emotional and selection process. Self-efficacy in character there are major two: first, self-efficacy has certain areas of a second, self-efficacy is dynamic. Teacher efficacy there is a key factor to explain the motivation of teachers.

\section{Value of Teaching Efficacy}

Interpretation of teaching effectiveness from the perspective of educational theory, self-efficacy directly reflects the physical and mental health status of teachers, so that teachers pay attention to small problems that exist around, because in a campus environment, to provide alternative self-efficacy information for students The main example is the companion and teacher. While teachers also need to cultivate a sense of students' self-efficacy in teaching practice, the proper use of external force to strengthen the experience witnessed increase student success and effectiveness of the use of role models provide alternative information. From the research results of education, the teaching effectiveness of student behavior and learning has an important influence, teaching effectiveness of teachers teaching practice presented in varying degrees, reflecting differences in each teacher teaching efficacy [2]. Teachers in the teaching practice of teaching how to show efficacy will make the students what effect. Therefore, researchers believe education teachers 
teaching efficacy research is the study of how to improve and enhance the quality of teaching an important part of universities. This helps improve the quality of education, but also help to improve the quality of teachers and teaching ability.

\section{Factors Affecting the Sense of Teaching Efficacy in West Private Colleges}

Teaching Ability and Teaching Experience. University Teachers 'Teaching Efficacy is also reflected in teaching ability, and teachers' personal experiences and growth capability is inextricably linked, as teachers in private colleges and universities in western regions facing students and reduce competitive pressures, as well as lack of funds to bring education teacher identity is difficult issues identified, and can not enjoy the treatment of teachers and other public reality. As western Private University Teachers also need to overcome a variety of internal and external pressures, show teaching efficacy teachers.

Teachers Teaching Environment and Self-Exploration. In our university teachers teaching ability and skills to a large extent from the teacher's self-exploration, a large number of teachers by reading books and regular exchange of teaching experience and the other teachers, observe and learn other ways to increase improve teaching self-efficacy. The teaching and learning environment for university teaching quality assessment also has an important influence. Hence, the need to promote the exchange of experiences between teachers teaching strengthen the construction of evaluation system of teaching in order to improve teaching effectiveness to provide a good learning environment.

Enhance Teachers' Teaching Efficacy of Significance. Self-efficacy is different from personal ability, for university teachers in terms of their self-efficacy refers to whether competent teaching. This includes teaching ability of teachers and subjective confidence and so on. Self-efficacy in a way that is the starting point is the end, is a teacher in the face of difficulties and tasks to deal with the whole process and the complete results. While teachers' self-efficacy also reflects the teacher's mental state [3]. So, to improve teaching effectiveness, which improve the teaching ability and capacity to respond to face difficulty. Especially for the Western Region Private College teachers, with a healthy and positive attitude to face the practical difficulties, beyond the difficulties to demonstrate its optimistic faith, so that students get more benefit from spiritual teachers in the profession stick.

\section{Enhance the Sense of Private Colleges in Western Teacher Effectiveness}

Sound Teaching Evaluation System. West through sound teaching evaluation system can be combined with school teachers in private colleges and universities from many angles actual teaching efficiency of teachers are evaluated. Teaching Evaluation System in sound takes fully into account the differences among teachers, and professional requirements will be incorporated into the structure and status of teaching discipline and other evaluation criteria system, pay attention to teachers' efforts to investigate and realized the situation and practice of binding targets to be adjusted accordingly promote teaching efficiency improvements. Secondly, when evaluating teaching efficiency of teachers, but also the performance of the combination of surveys and routine observation and application of questionnaires and data analysis and other forms of nature and extent of the analysis, in order to make teaching effective teacher efficacy evaluation [4].

Reward Effective Teachers Sense. The effective evaluation, based on the teaching efficacy of teachers to give a relatively high sound teaching evaluation system by appropriate incentives, to promote the professional development of teachers and improve teaching ability and professional level, similar to other teachers also have an exemplary role. Further, as the western private colleges also need to actively expand the development of private education, efforts to improve the educational level of private education, private schools teachers, public teachers should be in accordance with standards for social security institutions. Faced with lack of prejudice to the benefit of students and teachers of University of income, we can also provide high-quality and diverse selection of educational services by encouraging private schools to form its own characteristics by 
appropriately lowering the threshold to increase school students, in order to improve the income of private teachers in western region .

Timely Adjustment of Teaching Measures. Through the teaching efficiency can facilitate the effective evaluation of feedback within teacher evaluation results, and promote teachers to improve their teaching methods in order to improve the quality of teaching, but also help teachers improve their knowledge structure, promote the upgrading of teaching ability. Colleges and universities to improve teaching skills and techniques by directing teachers to provide more opportunities for post-graduate teachers to effectively enhance teaching effectiveness, and promote teachers to improve teaching methods and teaching methods.

Teachers Promote the Exchange of Learning. Teachers in the teaching practice can give full play to the exemplary role of teachers by strengthening interaction between teachers and lectures of inspection, as well as means of strengthening the administrative supervision of the teaching efficacy of teachers can lower research and by organizing lectures to find problems in teaching. By strengthening this interaction between teachers and lectures of inspection, which will help teachers improve teaching methods to improve teaching effectiveness. At the same time promote exchanges between teachers, but also through class competitions and teaching quality assessment activities, reward outstanding teachers do a good job teaching demonstration pilot work, in order to enhance teachers' sense of honor and organize student teacher named favorite activities. Further evaluation of teaching effectiveness can also organize seminars teaching efficacy analysis for teachers to improve the quality of teaching.

\section{Strengthen Teacher Self-Reflection Capability}

Cultured Self-Reflection Capabilities. Experience and reflection are two essential elements of a teacher to grow and cultivate the ability to help teachers examine teacher reflection and objective evaluation of their own teaching and teaching ability action to promote the ability to reflect is an effective way to improve teaching ability.

Teachers' Self-Evaluation of Teaching Efficacy. Teachers in the teaching practice of teaching efficacy self-evaluation, set the project evaluation and indicators for teaching various aspects of the application of self-evaluation questions in order to find their own deficiencies in the process of teaching the correct positioning of their own teaching activities. Self-evaluation of teachers through teacher facilitates accurate understanding of the teaching situation, where lack of serious reflection. While setting evaluation items and indicators also help teachers teaching experience are summarized in the longer time span, the teachers of their teaching methods for diagnosis by analyzing the strengths and weaknesses to help and adjust improvements. Teacher reflection in Reflection by strengthening the exchange of experiences between teachers, but also can promote teachers to learn from other experienced teachers teaching methods achieve common progress, this can contribute to a sense of self-evaluation of teaching performance enhancement.

Strengthen the Teaching Process Analysis. The need for analysis of the entire teaching process in teaching reflection, to analyze the teacher in the teaching activities made the problems, the relationship between its causes and consequences, easy to select multiple perspectives to analyze and interpret the teaching process. Therefore, the analysis of the causes and consequences of the teachers and the entire process, help teachers teaching success and realistic look at the results of a careful analysis of teaching "teach" reasons. Also look for in terms of "learning" the reason for the occurrence of the problem to make a rational analysis and evaluation, form the correct teaching management approach allows teachers through reflective analysis teaching management model, on which the teaching process analysis and management help to teachers to improve teaching quality and enhance student test scores. Teachers reflect on the analysis by combining the characteristics of their teaching and teaching requirements, improve control of management practices throughout the teaching process, so that teachers can know in teaching practice "what to teach, how to teach."

Improve Teachers' Mental Health. Improve teaching effectiveness, which is a key element to improve the mental health of teachers, teachers can help improve their mental health in a positive, healthy attitude put into work, especially in western areas teachers need to take the initiative and 
individual potential, improve teaching effectiveness and improve their teaching efficacy [5]. Universities in the Western Region as a teacher teaching in the face of difficulties, by actively respond to find ways and means to resolve the difficulties, to take the initiative optimistic state of mind to face external pressures and wages problem in reality, to gain more and increase the chances of success Teaching Efficacy. In the area of private Western College teachers in their efforts to improve their mental health, but also the need for their school and community to provide a better learning environment, and increase efforts to support teachers in private colleges and universities, in order to more effectively promote the western region of Private University Teachers improve mental health, thus contributing to the continuous appreciation of their teaching effectiveness.

\section{Conclusion}

In summary, the development of the western region by increasing private universities teaching efficacy of college teachers in order to achieve the purpose of universities to enhance the teaching efficiency in teaching practice. While the western region of Private Colleges face external pressures and challenges, through sound evaluation system for teachers and reward effective teachers can sense, and by timely measures to adjust the teaching and training of teachers and other methods to reflect the ability to promote exchanges among teachers in order to keep each other and other private education sustainable development trends, so enhancing teaching efficacy can not only build a high-level team of teachers, but also highlight the characteristics of the western region to promote private the continues development of education in western regions.

\section{References}

[1] Su Qinjing. Admire Places Research on Teaching Efficacy of College Teachers and Improve The Effect of Countermeasures. Education Research Programs, 2013,6 (28): 21-22.

[2] Wang Guoliang. College English Teacher Efficacy Review Domestic Empirical Research (2008-2013). Education Review, 2014,5 (4): 48-51.

[3] Xie Nan, Zhou Tao, Deng Renli. Situation of College Teachers Nursing Efficacy and Its Influencing Factors. Clinical, 2013,7 (2): 164-168.

[4] Zhou Li. Teaching Efficacy Tibet College English Study. Education, 2013,8 (4): 34-35.

[5] Cong Yuyan. Strengthen Management to Enhance Teaching Universities Efficacy. Chinese Higher Education, 2013,11 (Z1): 59-61. 